\title{
Acceptability of Flipped Classroom Approach in Ophthalmology Clerkship Teaching
}

Guangming Jin ( $\sigma_{\text {jingm@@mail2.sysu.edu.cn ) }}$

Sun YAT-Sen University https://orcid.org/0000-0001-9994-6338

Charlotte Aimee Young

University of California Berkeley School of Public Health

Aiming Chen

The Fifth Affiliated Hospital of Sun Yat-sen University

\section{Yuxian Zou}

Sun Yat-Sen University Zhongshan Ophthalmic Center

\section{Danying Zheng}

Sun Yat-Sen University Zhongshan Ophthalmic Center

\section{Research article}

Keywords: Education; Flipped classroom; Ophthalmology

Posted Date: May 20th, 2019

DOI: https://doi.org/10.21203/rs.2.9684/v1

License: (c) (1) This work is licensed under a Creative Commons Attribution 4.0 International License. Read Full License 


\section{Abstract}

Purpose Flipped classroom is a new teaching model which has received a large amount of attention, but the overall acceptability and effectiveness of this approach in different fields of medical education is still controversial. The purpose of this study was to evaluate the acceptability of the flipped classroom in ophthalmology clerkship teaching. Methods A learning model of a traditional lecture-based approach was changed to a flipped classroom approach for a group of 5-year Clinical Medicine Program students. The flipped classroom included provided pre-session learning resources and objectives before each weekly session. In-session activities emphasized knowledge application and active learning strategies. Data regarding students' acceptability of the new approach was obtained by anonymous questionnaires that students filled out immediately after class. Results Feedback was received from 94/94 (100\%) medical students. $62.8 \%(59 / 94)$ of respondents preferred the flipped classroom approach over the traditional approach. Interacting with peers and needing more time/effort for preparation were the aspects liked most and least (respectively) for the flipped classroom by students. Flipped classroom was considered better in helping to train students' ability in clinical problem solving, the search and study of literature, cooperating with others, academic exchange, and self-directed learning when compared with the traditional approach. The flipped classroom approach was thought to be a more effective and inspiring way of teaching $(P<0.001)$. Both males and females thought the flipped classroom was a useful way to help students find and solve problems, consider problems comprehensively, learn from literature, and cooperate with others. Conlusions The flipped classroom has a good acceptability in ophthalmology clerkship teaching. Further evaluation is needed when it be implemented

\section{Introduction}

Flipped classroom is a new teaching model that was first attempted by chemistry teacher Jon Bergmann and Aaron Sams[ 1, 2] and has received a large amount of attention in medical education.[3-8] In the flipped classroom, multiple resources including the print, audio, video and network resources were provided to the students prior to class, and student-centered learning activities such as case scenario analysis are performed in the class.[9] Teachers do not drive the teaching process in the flipped classroom, but spend their time guiding collaborative learning, problem-based learning, and the application of knowledge. Also, students are required to play an active role in the classroom rather than passively absorbing lecture materials. The flipped classroom allows students to freely choose the most suitable study manner for themselves and converts the passive acceptance in traditional classroom approach into self-exploration while respecting the individual characteristics of cognitive learning. [10] Previous studies have shown that flipped-class pedagogy could enhance students' collaborative-learning strategies and could result in better learning outcomes.[10-12]

Ophthalmology clerkship is an important procedure for clinical skill training and is essential to all medical practitioners, as the visual system is bound to other body systems, and eye diseases can be a key clue for systemic disease such as hypertension and diabetes. Though the need for ophthalmic care providers is increasing, ophthalmology education has been marginalized as a consequence of decreasing curriculum 
time.[13] This requires ophthalmic educators to seek a more effective approach to disseminate complex knowledge to students. Noting the previous reports in other subject education, flipped classroom may be an effective way to solve this dilemma in ophthalmology clerkship education.

Although there is some empirical support for active learning strategies in medical education, $[4,3,9,14]$ it is rare that studies have focused on the application of the flipped classroom approach in the context of ophthalmologic education. Additionally, the overall acceptability and effectiveness of this approach in different fields of medical education is still controversial[ $4,15,16]$, and the flipped classroom approach requires further investigation to evaluate its feasibility before being applied to specific courses. In this study, we introduced the flipped classroom to ophthalmology education and evaluated the students' attitudes and preferences in an effort to provide an alternative, potentially better approach that can be implemented in ophthalmologic education.

\section{Methods}

\section{Participants}

94 medical students of a 5-year Clinical Medicine Program participated in the study. Prior to the study, students had completed and attended the required lectures at Sun Yat-sen University before attending clinical clerkship at Zhongshan Ophthalmic Center, Guangzhou. Prior to enrollment, study participants were not informed of the modified course format. Approval was obtained by the institutional review board of Zhongshan Ophthalmic Center of Sun Yat-sen University. Written informed consent was obtained from all students.

\section{Procedure}

Both traditional and flipped classroom courses were taught entirely in Chinese. Two parts of the program (ocular trauma and glaucoma) were taught using the flipped classroom method, and the remaining sections (amongst them cataract and cornea disease) were taught using the traditional classroom method.

In the traditional, lecture-based classroom, students sat for a 45-minute didactic lecture followed by an instructor led question and answer session. A homework assignment was posted after lecture to assess lecture content comprehension. This homework assignment was identical to the one assigned in the flipped classroom. Instructors encouraged students to review the ocular trauma (or glaucoma) chapter of their textbook before beginning the homework assignment. Homework was always due one week after class, and instructors would provide feedback on each homework assignment. A discussion about graded homework would take place, where students had the opportunity to request correct answers and ask to work through challenging problems with the instructor. 
In the flipped classroom setting, students were divided into small groups of 3 to 4 students with a student leader assigned to each group. While in the traditional, lecture based classroom students were not given assignments relevant to the upcoming lecture, during the sections taught in the flipped classroom, students were asked to complete certain tasks prior to class. Students were asked to watch a prerecorded video lecture online regarding the lecture topic 3 days before the class. Instructors then sent out identical clinical cases and related questions to each group, with the expectation that a six-slide PowerPoint presentation would be prepared by each small group regarding the clinical case. The content of the PowerPoint would include a presentation of the assigned case and answers to the related questions. During the presentation, instructors encouraged participation, questions, and opposing opinions from other groups. Presenters were encouraged to propose additional questions and present them to the class. Presentations were concluded with a summary and review of all questions by the instructor.

Data regarding students' opinions and attitudes toward traditional and flipped classroom were obtained by questionnaires that students filled out immediately after class. The said questionnaire was adapted from Paul Ramsden's Course Experience Questionnaire (CEQ)[17] and Biggs' Study Process questionnaire[ 18]. The questionnaire covered questions focused on aspects of the classroom that were most favored and not favored by students, perceived utility of the teaching format, the overall learning experience, and perceived utility of the provided resources/activities, as well as perceived improvement in different skill areas. The questionnaire used a standard 5-point Likert scale that ranges from a score of 1 ("strongly disagree" or "not useful at all") to a score of 5 ("strongly agree" or "extremely useful").

\section{Statistical Analysis}

Non-normal distribution quantitative data are presented as proportions or median values with interquartile ranges (IQRs). A Chi-square test was used to compare perceived utility and learning experience between different teaching methods and between different genders. All data analyses were performed using Stata 14.0 software (Stata crop, College Station, TX).

\section{Results}

Among the 94 medical students that participated in the present study, all 94 filled out and completed questionnaires. The mean age of the participants was 21.6 years old, with females accounting for $62.8 \%$ (52/94) of the total subjects. $62.8 \%(59 / 94)$ of respondents preferred the flipped classroom approach over the traditional approach and 3.2\% (3/94) like both the flipped classroom approach and the traditional approach (Figure 1).

The aspects of different teaching methods liked most and least by students are summarized in Table 1 . "Information could be presented clearly" (39.4\%) and "lectures seems to be copied from textbooks" $(29.0 \%)$ were the aspects liked most and least, respectively, for the traditional classroom by students. In 
comparison, "interaction with peers and senior medical officers" (33.0\%) and "more time/effort for preparation" (32.3\%) were the aspects liked most and least, respectively, for the flipped classroom by students.

Perceived effectiveness of the traditional and flipped classroom approach in advancing students in different skills are summarized in Table 2. From the descriptive statistics shown in Table 2, compared to the traditional classroom, the flipped classroom model received significantly higher scores in its perceived effectiveness in developing the following skills: "clinical problems solving" ( $P<0.001)$, "search and study of literature" ( $P<0.001)$, "cooperating with others" $(P<0.001)$, "academic exchange" $(P<0.001)$, "selfdirected learning" $(P<0.001)$. More specifically, in the category titled "self-directed learning", the flipped classroom obtained a higher perceived utility rating than the traditional classroom (Median rating 4, IQR 3-4).

Table 3 shows a comparison of learning experiences in the traditional classroom versus the flipped classroom based on student answers. Compared to the traditional classroom, flipped classroom was thought to be a "very effective and inspiring way of teaching" $(P<0.001)$, "a better teaching method which should be generalized" ( $P<0.001)$, "a teaching method that makes me more likely to participate" $(P<0.001)$, "an approach that is conducive to a more in-depth study of professional knowledge" $(P<0.001)$ and "a more relaxed and interesting way of learning" $(P<0.001)$.

Respondents' perceived utility of learning resources, activities and self-evaluation of improvement in different skill areas was summarized in Table 4. The result shows that females scored certain items higher than males, especially in the section of "in-session learning activities". Moreover, in the section of "evaluating improvement" both males and females scored these items highly.

\section{Discussion}

In this study our team applied both the traditional and flipped classroom model in different content sections of the course and sought to evaluate the outcome. Based on the parameters that were quantitatively assessed (aspects of the classroom that were most favored and not favored by students, perceived utility of the teaching format, the overall learning experience, and perceived utility of the provided resources/activities, perceived improvement in different skill areas), we found that the flipped classroom was favored over the traditional classroom setting.

Through our surveys, we found that the aspect that the highest proportion of students liked about the flipped classroom was the "interaction with peers and senior medical officers". It has been hypothesized that interaction and group-based learning promotes experiential learning, as well as exposes and pushes students to apply course content. [19,20] We also suspect that because the flipped classroom model provides the opportunity for discussion and group-work, students naturally step into roles such as team players, presentation leaders, content creators, and become active contributors in their knowledge acquisition versus passive listeners. To add, the opportunity to interact with senior medical staff and experts instead of simply listen to their lectures allows the students a sense of intimacy and comfort with 
the experts, promoting open communication and community with the experts, and by extension, other senior medical staff. This narrows the distance between instructor and student, and has been shown to lessen the fear of participating to avoid appearing unintelligent by professors of peers.[ 21, 22]

The category that was liked by the second highest proportion of the class was "self-directed learning". This category also scored the highest in its perceived utility in the flipped classroom. In contrast to expert or instructor-directed learning, self-directed learning is a method where students have more control over how and when they receive their knowledge, and their experience can be tailored to each student. In the traditional classroom, students that do not absorb information effectively through lecture-based format (that simultaneously communicates visual and auditory information) may be excluded from the learning process and fall behind their peers. In the flipped classroom format, students that learn better from lectures can re-watch lecture videos, and students that prefer acquiring knowledge from textbooks and handouts can consult these resources. This is one advantage that flipped classroom has over the traditional classroom format. Not only this, but "self-directed learning" was also recognized as a perceived value of flipped classroom as well. Students rated the flipped classroom's ability to help train students in self-directed learning higher than for the traditional classroom. Students not only liked and enjoyed the self-directed learning aspect of the classroom, but also responded that the flipped classroom is the environment that is more conducive to self-directed learning. This not only shows further value in the flipped classroom method, but also illustrates the students' interest and desire to develop skills and strategies for self-directed learning.

Flipped classroom was also rated higher than the traditional classroom in its perceived effectiveness in advancing students in their ability to search and study literature. In the flipped classroom approach, in order to prepare for the small-group clinical presentations, students had to problem-solve by referencing lecture notes, textbooks, as well as outside literature. The flipped classroom model intrinsically pushes students to seek answers outside of classroom provided resources, creating an environment where the phenomenon of "Problem-based learning" is fostered, a student centered pedagogy where students work in groups to solve a content relevant problem.[23,24] Medical professionals frequently need to consult and reference literature to seek knowledge and answers, and is undoubtedly an invaluable skill that, if mastered, will benefit students throughout their medical careers.

The overall learning experience of the flipped classroom scored higher than the traditional classroom method in every category in the survey. One interesting finding is that when asked to rate whether the flipped or traditional classroom was "A relaxed and interesting way to learn", students rated the flipped classroom higher than the traditional classroom, despite there being more pre-class preparation in the flipped classroom approach. This finding is significant when taken with another finding of our study that an aspect liked least by students in the flipped classroom was that it required "More time/effort for preparation". This implies that although there is the expectation that students complete more work prior to class, students find the time spent in the classroom engaging and relaxing. Though several flipped classroom studies have noted that pre-class learning and assignment completion have been a challenge, 
[25-27] our study finds that despite this challenge, students still find the time in the flipped classroom interesting and that the flipped classroom is still very much welcomed.

Aside from the post-class quizzes, students overall rated 'In-session learning activities' highly for their perceived effectiveness as a learning resource. This finding is quite telling, showing that students found case scenarios, small group discussions, and group presentations all "quite useful". Although it has been shown that small group discussions are not always successful in fostering useful discussions in the classroom, $[21,28]$ our study finds that students perceive a great deal of usefulness from these in-class activities.

Although there certainly were aspects of the flipped classroom that were favored by students, there were aspects of the traditional classroom that were liked as well, namely, that "information could be presented clearly" and "key points could be emphasized and well explained". This finding is also supported by other studies, showing that students do enjoy having class content presented to them in an organized way. We also suspect that having key points emphasized by the professor allows students to gain a grasp of what key topics are especially valued by that professor, perhaps for presentation or exam score purposes. To add, in the flipped classroom model, though students watch pre-recorded lectures by professors and expert that were presented in lecture format, they would not have had the opportunity to ask questions immediately in the moment if they found a point unclear. It is likely that students enjoyed the opportunity of clarifying points with a professor in real-time in the traditional classroom.

The aspect liked least in the flipped classroom method, "more time/effort for preparation" was another significant finding, though not altogether surprising. In the flipped classroom method, students do prepare for class beforehand by reviewing lecture material on their own, and come to class having already familiarized themselves with the class topic. We suggest that pre-class resources be clear and concise, and that different approaches (videos and text) be used to maximize the students' understanding during their study time.

Our study was also interested in exploring whether there would be a variability in the feedback provided by males and females, as it has been cited that men and women do respond differently to classroom approaches.[29-31, 21] We found that there was no statistical difference between male and female responses, suggesting that the flipped classroom is welcomed by both males and females.

One limitation of our study is that the flipped classroom was applied to only sections of the ophthalmology clerkship content, and so does not take into account how flipped classroom works for all ophthalmology topics. Indeed, it would be presumptuous to assume that flipped classroom would work equally well for all areas of study in ophthalmology. A second limitation of our study is that it was applied only to a 5-year Clinical Medicine Program, and does not investigate its application in other program such as an 8-year Clinical Medicine Program, Bachelor of Medicine Program, and Bachelor of Surgery Program (MBBS). However, the standard 5-year Clinical Medicine Program accounts for the largest proportion of medical student in China, and so the results of the present study are quite representative. 
The flipped classroom method has been applied and reported to be successful in other areas of teaching [ 32-34]but rarely reported for ophthalmology clerkship teaching. This, coupled with the particularity of Chinese education, emphasizes the demand for studying the value and feasibility of the flipped classroom. In our study, ophthalmology trainees generally scored the flipped classroom higher than the traditional classroom, from categories in "better learning experience" to "better improvement in different skill areas". The high distribution of students that favored the flipped classroom over the traditional classroom shows a strong preference for the flipped classroom and high acceptability. We strongly hypothesize that implementation of the flipped classroom approach would be very much welcome. When proposing new directions in educational methods, it is essential that they are developed thoughtfully and thoroughly studied before formal implementation. We believe that the flipped classroom has potential to be successful in academic ophthalmology training, and further research will shine a light on how this can become a widespread reality.

\section{Declarations}

\section{Compliance with ethical standards}

\section{Conflict of interest}

The authors declare no competing financial interests.

\section{Ethical approval}

All procedures performed in studies involving human participants were in accordance with the ethical standards of the institutional research committee and with the Declaration of Helsinki.

\section{Informed consent}

Informed consent was obtained from all individual participants included in the study.

\section{Funding}

This study was supported Teaching Research Funds of Zhongshan Ophthalmic Center.

\section{References}

1. McDonald K, Smith CM (2013) The flipped classroom for professional development: part I. Benefits and strategies. J Contin Educ Nurs 44 (10):437-438. doi:10.3928/00220124-20130925-19

2. Pierce R, Fox J (2012) Vodcasts and active-learning exercises in a "flipped classroom" model of a renal pharmacotherapy module. Am J Pharm Educ 76 (10):196. doi:10.5688/ajpe7610196

3. Sharma N, Lau CS, Doherty I, Harbutt D (2015) How we flipped the medical classroom. Med Teach 37 (4):327-330. doi:10.3109/0142159X.2014.923821 
4. Tan E, Brainard A, Larkin GL (2015) Acceptability of the flipped classroom approach for in-house teaching in emergency medicine. Emerg Med Australas 27 (5):453-459. doi:10.1111/1742-6723.12454

5. The flipped classroom for medical students.

6. Chiu HY, Kang YN, Wang WL, Huang HC, Wu CC, Hsu W, Tong YS, Wei PL (2017) The Effectiveness of a Simulation-Based Flipped Classroom in the Acquisition of Laparoscopic Suturing Skills in Medical Students-A Pilot Study. J Surg Educ. doi:10.1016/j.jsurg.2017.07.007

7. Sheppard ME, Vitalone-Raccaro N, Kaari JM, Ajumobi TT (2017) Using a flipped classroom and the perspective of families to teach medical students about children with disabilities and special education. Disabil Health J. doi:10.1016/j.dhjo.2017.03.012

8. Cheng X, Ka Ho Lee K, Chang EY, Yang X (2017) The "flipped classroom" approach: Stimulating positive learning attitudes and improving mastery of histology among medical students. Anat Sci Educ 10 (4):317-327. doi:10.1002/ase.1664

9. Prober CG, Heath C (2012) Lecture halls without lectures-a proposal for medical education. The New England journal of medicine 366 (18):1657-1659. doi:10.1056/NEJMp1202451

10. van Vliet EA, Winnips JC, Brouwer N (2015) Flipped-Class Pedagogy Enhances Student Metacognition and Collaborative-Learning Strategies in Higher Education But Effect Does Not Persist. CBE Life Sci Educ 14 (3). doi:10.1187/cbe.14-09-0141

11. Rui Z, Lian-rui X, Rong-zheng Y, Jing Z, Xue-hong W, Chuan Z (2017) Friend or Foe? Flipped Classroom for Undergraduate Electrocardiogram Learning: a Randomized Controlled Study. BMC Medical Education 17 (1). doi:10.1186/s12909-017-0881-8

12. Gorres-Martens BK, Segovia AR, Pfefer MT (2016) Positive outcomes increase over time with the implementation of a semiflipped teaching model. Adv Physiol Educ 40 (1):32-37. doi:10.1152/advan.00034.2015

13. Succar T, Grigg J, Beaver HA, Lee AG (2016) A systematic review of best practices in teaching ophthalmology to medical students. Surv Ophthalmol 61 (1):83-94.

doi:10.1016/j.survophthal.2015.09.001

14. Periyakoil VS, Basaviah $P$ (2013) The flipped classroom paradigm for teaching palliative care skills. The virtual mentor : VM 15 (12):1034-1037. doi:10.1001/virtualmentor.2013.15.12.medu1-1312

15. Whillier S, Lystad RP (2015) No differences in grades or level of satisfaction in a flipped classroom for neuroanatomy. J Chiropr Educ 29 (2):127-133. doi:10.7899/JCE-14-28

16. Tolks D, Schafer C, Raupach T, Kruse L, Sarikas A, Gerhardt-Szep S, Kllauer G, Lemos M, Fischer MR, Eichner B, Sostmann K, Hege I (2016) An Introduction to the Inverted/Flipped Classroom Model in 
Education and Advanced Training in Medicine and in the Healthcare Professions. GMS J Med Educ 33 (3):Doc46. doi:10.3205/zma001045

17. Ramsden $P$ (1991) A performance indicator of teaching quality in higher education: The Course Experience Questionnaire. Studies in Higher Education 16 (2):129-150.

doi:10.1080/03075079112331382944

18. Biggs JB (1987) Study Process Questionnaire Manual. Student Approaches to Learningand Studying.

19. Michaelsen LK, Sweet M (2008) The essential elements of team-based learning. New Directions for Teaching and Learning 2008 (116):7-27. doi:10.1002/tl.330

20. Birmingham C, McCord M (2004) Group process research: Implications for using learning groups. Team-based learning: A transformative use of small groups in college teaching:73-93

21. Fassinger PA (1996) Professors' and students' perceptions of why students participate in class. Teaching sociology:25-33

22. Clarridge PB, Berliner DC (1991) Perceptions of student behavior as a function of expertise. The Journal of Classroom Interaction:1-8

23. Hung W, Jonassen DH, Liu R (2008) Problem-based learning. Handbook of research on educational communications and technology 3:485-506

24. Kilroy D (2004) Problem based learning. Emergency medicine journal 21 (4):411-413

25. Moffett J (2015) Twelve tips for "flipping" the classroom. Medical teacher 37 (4):331-336

26. Prunuske AJ, Batzli J, Howell E, Miller S (2012) Using online lectures to make time for active learning. Genetics 192 (1):67-72

27. Sharma N, Lau C, Doherty I, Harbutt D (2015) How we flipped the medical classroom. Medical teacher $37(4): 327-330$

28. Cornelius R, Gray JM, Anne P Constantinople. 1990." Student-Faculty Interaction in the College Classroom.". Journal ofResearch and Development in Education 23:189-197

29. Sullivan P (2001) Gender differences and the online classroom: Male and female college students evaluate their experiences. Community College Journal of Research \&Practice 25 (10):805-818

30. Crombie G, Pyke SW, Silverthorn N, Jones A, Piccinin S (2003) Students' perceptions of their classroom participation and instructor as a function of gender and context. The journal of higher education 74 (1):51-76 
31. Lawrenz F (1987) Gender effects for student perception of the classroom psychosocial environment. Journal of Research in Science Teaching 24 (8):689-697

32. Pierce R, Fox J (2012) Vodcasts and active-learning exercises in a "flipped classroom" model of a renal pharmacotherapy module. American journal of pharmaceutical education 76 (10):196

33. Tan E, Brainard A, Larkin GL (2015) Acceptability of the flipped classroom approach for in-house teaching in emergency medicine. Emergency Medicine Australasia 27 (5):453-459

34. Kannan J, Kurup V (2012) Blended learning in anesthesia education: current state and future model. Current Opinion in Anesthesiology 25 (6):692-698

\section{Tables}

Table 1. Aspects of traditional approach and flipped classroom liked most and least by respondents 


\section{Teaching} approach

Traditional classroom
Aspects liked MOST

Hearing a passionate

expert speak

Less preparation

necessary, easier to be

passive

Convenience in

speaking with experts
Proportion

(\%)

5.32

12.8

7.45
Aspects liked

LEAST
Proportion

(\%)

21.5

Boredom and

even "sleep-

inducing"
Didactic nature of

delivery from

some teachers

Lectures seems to

be copied from

textbooks

20.4

29.0

\begin{tabular}{|c|c|c|c|c|}
\hline & $\begin{array}{l}\text { Key points could be } \\
\text { emphasized and well } \\
\text { explained }\end{array}$ & 35.1 & $\begin{array}{l}\text { Lecture with } \\
\text { limited interaction } \\
\text { on a dry topic }\end{array}$ & 10.7 \\
\hline & $\begin{array}{l}\text { Information could be } \\
\text { presented clearly }\end{array}$ & 39.4 & $\begin{array}{l}\text { Long session } \\
\text { times }\end{array}$ & 18.3 \\
\hline \multirow[t]{5}{*}{$\begin{array}{l}\text { Flipped } \\
\text { classroom }\end{array}$} & $\begin{array}{l}\text { Discussing real-life } \\
\text { problems and cases }\end{array}$ & 20.2 & $\begin{array}{l}\text { Large volume of } \\
\text { pre-session } \\
\text { materials }\end{array}$ & 5.38 \\
\hline & $\begin{array}{l}\text { Interaction with peers } \\
\text { and senior medical } \\
\text { officer }\end{array}$ & 33.0 & $\begin{array}{l}\text { More time/effort } \\
\text { for preparation }\end{array}$ & 32.3 \\
\hline & $\begin{array}{l}\text { Using knowledge to } \\
\text { solve clinical scenarios }\end{array}$ & 6.38 & $\begin{array}{l}\text { Easy to be } \\
\text { digressive }\end{array}$ & 30.1 \\
\hline & Self-directed learning & 24.5 & Limited time & 9.68 \\
\hline & Small group learning & 11.7 & $\begin{array}{l}\text { Less learner } \\
\text { satisfaction } \\
\text { without } \\
\text { preparation }\end{array}$ & 22.6 \\
\hline
\end{tabular}

Table 2. Perceived effectiveness of traditional and flipped classroom approach in advancing students in different skills 


\begin{tabular}{|c|c|c|c|c|c|}
\hline & \multicolumn{2}{|l|}{$\begin{array}{l}\text { Traditional } \\
\text { classroom }\end{array}$} & \multicolumn{2}{|l|}{$\begin{array}{l}\text { Flipped } \\
\text { classroom }\end{array}$} & \multirow[t]{2}{*}{ P-Value } \\
\hline & Median rating & IQR & $\begin{array}{l}\text { Median } \\
\text { rating }\end{array}$ & IQR & \\
\hline Clinical problems solving & 3 & $2-3$ & 3 & $3-4$ & $<0.001^{\star}$ \\
\hline Search and study of literature & 2 & $1-3$ & 3 & $3-4$ & $<0.001^{\star}$ \\
\hline Cooperating with others & 2 & $1-3$ & 3 & $3-4$ & $<0.001^{\star}$ \\
\hline Academic exchange & 3 & $2-3$ & 3 & $3-4$ & $<0.001^{\star}$ \\
\hline $\begin{array}{l}\text { Developing self-confidence in } \\
\text { course topics }\end{array}$ & 3 & $2-4$ & 3 & $3-4$ & 0.0553 \\
\hline Self-directed learning & 3 & $2-4$ & 4 & $3-4$ & $<0.001^{*}$ \\
\hline \multicolumn{6}{|c|}{ *Statistically significant. $1=$ not useful at all; $5=$ extremely useful. IQR: interquartile range; } \\
\hline & \multicolumn{2}{|c|}{$\begin{array}{l}\text { Traditional } \\
\text { classroom }\end{array}$} & \multicolumn{2}{|c|}{$\begin{array}{l}\text { Flipped } \\
\text { classroom }\end{array}$} & \multirow[t]{2}{*}{ P-Value } \\
\hline & $\begin{array}{l}\text { Median } \\
\text { rating }\end{array}$ & IQR & $\begin{array}{l}\text { Median } \\
\text { rating }\end{array}$ & IQR & \\
\hline $\begin{array}{l}\text { It's a very effective and inspiring way } \\
\text { of teaching }\end{array}$ & 3 & $3-4$ & 4 & $4-4$ & $<0.001^{*}$ \\
\hline $\begin{array}{l}\text { This teaching method should be } \\
\text { generalized }\end{array}$ & 3 & $3-3$ & 4 & $3-4$ & $<0.001^{*}$ \\
\hline $\begin{array}{l}\text { This teaching method makes me } \\
\text { more likely to participate }\end{array}$ & 3 & $3-4$ & 4 & $4-4$ & $<0.001^{*}$ \\
\hline $\begin{array}{l}\text { This approach is conducive to a } \\
\text { more in-depth study of professional } \\
\text { knowledge }\end{array}$ & 3 & $3-4$ & 4 & $3-4$ & $<0.001^{\star}$ \\
\hline $\begin{array}{l}\text { This is a relaxed and interesting way } \\
\text { of learning }\end{array}$ & 3 & $2-3$ & 4 & $3-4$ & $<0.001^{*}$ \\
\hline
\end{tabular}

*Statistically significant. $1=$ strongly disagree; 5 =highly agree. IQR: interquartile range;

Table 4. Perceived utility of learning resources, activities and evaluating improvement in different skill areas 


\begin{tabular}{|c|c|c|c|c|}
\hline Total & & Male & & Female \\
\hline $\begin{array}{l}\text { Median } \\
\text { rating }\end{array}$ & IQR & $\begin{array}{l}\text { Median } \\
\text { rating }\end{array}$ & IQR & $\begin{array}{l}\text { Median } \\
\text { rating }\end{array}$ \\
\hline
\end{tabular}

\section{Pre-session learning resources}

\begin{tabular}{|c|c|c|c|c|c|c|c|}
\hline PowerPoint slides & 3 & 3-4 & 3 & $3-4$ & 3 & $3-4$ & 0.746 \\
\hline Videos & 4 & 3-4 & 3 & $3-4$ & 4 & $3-4$ & 0.388 \\
\hline Bibliography & 3 & $3-4$ & 3 & $2-4$ & 3 & $3-4$ & 0.335 \\
\hline Excellent courses website & 3 & $2-3$ & 2.5 & $2-3$ & 3 & $2-3$ & 0.547 \\
\hline $\begin{array}{l}\text { Postgraduate } \\
\text { Demonstration Course } \\
\text { Website }\end{array}$ & 2 & $2-3$ & 2 & $2-3$ & 2 & $2-3$ & 0.905 \\
\hline \multicolumn{8}{|l|}{$\begin{array}{l}\text { In-session learning } \\
\text { activities }\end{array}$} \\
\hline Case scenarios & 4 & $3-4$ & 4 & $3-4$ & 4 & $3-4$ & 0.336 \\
\hline Small group discussion & 4 & $3-4$ & 3.5 & $3-4$ & 4 & $3-4$ & 0.239 \\
\hline Group presentation & 4 & $3-4$ & 3 & $3-4$ & 4 & $3-4$ & 0.979 \\
\hline Summary after class & 4 & $4-5$ & 4 & $4-5$ & 4 & $3-5$ & 0.249 \\
\hline Quizzes after class & 2.5 & $2-3$ & 2 & $2-3$ & 3 & $2-3$ & 0.358 \\
\hline
\end{tabular}

\section{Evaluating improvement}

Finding and solving problems

Taking initiate to solve problems

Considering problems comprehensively.

Learning from literature and working with others

Cultivating a critical way of 4 thinking

4

$\begin{array}{lllllll}4 & 4-4 & 4 & 4-4 & 4 & 4- & 0.553 \\ & & & & & 4.5 & \end{array}$

$\begin{array}{llllllll}4 & 4-4 & 4 & 4-4 & 4 & 4-4 & 0.796\end{array}$

4-4

4

4-4

4

4-5

0.595

4

4-5

4

4-4

4

4-5

0.240

3-4

4

$3-4$

4

3-4

0.341

$1=$ not useful at all; 5=extremely useful. IQR: interquartile range;

\section{Figures}




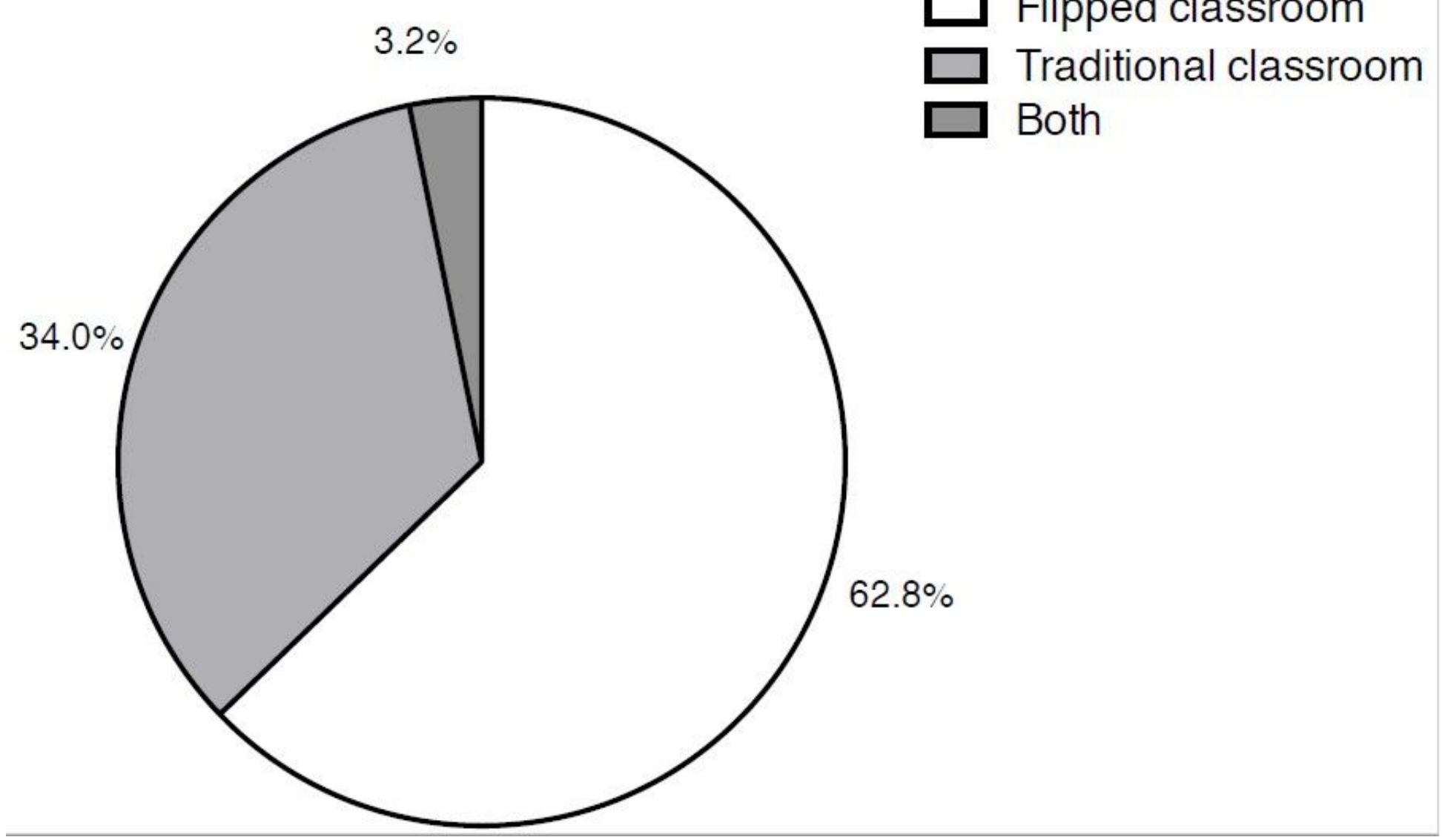

Figure 1

Distribution of preferred teaching model of the 5-year Clinical Medicine Program students 